\title{
Questões sobre a comunicação em uma sociedade de consumo: o papel das redes sociais na transformação do usuário em influenciador, um estudo de caso da @blogueiradebaixarenda
}

\section{Lilian Saback ${ }^{1}$}

\begin{abstract}
Resumo
O artigo contribui para o debate sobre o papel das redes sociais na transformação dos usuários em influenciadores digitas na sociedade de consumidores (BAUMAN, 2008). O trabalho faz um estudo de caso do perfil @blogueiradebaixa renda, produzido pela jovem Nathaly Dias, moradora do Morro do Banco, uma favela da Zona Oeste do Rio de Janeiro. Com base nos levantamentos da Global Digital e da consultoria Comscore, é feita uma análise da eficácia das postagens patrocinadas por marcas produzidas com a intenção de manter a essência da vida pessoal da blogueira.
\end{abstract}

Palavras-chave

Sociedade do Consumidores; Instagram; Blogueira de baixa renda; comunicação: \#publi

\section{Introdução}

Em janeiro de 2021, 150 milhões de brasileiros eram usuários de mídias sociais, o que equivalia a 70,3\% da população do país, de acordo com o relatório 2021 Global Digital, realizado pelo We Are Social e Hootsuite ${ }^{2}$. Já um estudo feito pela empresa de consultoria Comscore, afirma que em dezembro de 2020, os brasileiros passaram em média 47 horas navegando nas redes sociais ${ }^{3}$. Esses números contribuem para dar início a reflexão proposta neste artigo: pensar o papel das redes sociais na transformação de usuários em influenciadores programados para estimular o consumo de bens em uma sociedade imediatista, onde consome-se e descartase com a mesma intensidade. Surge uma nova forma de negócio que vem mobilizando os pesquisadores sobre comunicação.

\begin{abstract}
Com o aumento do acesso as redes sociais caracterizado pelo gradativo acesso à internet, ficou muito mais fácil uma pessoa anônima se tornar uma celebridade em um curto período de tempo, é nesse espaço que vemos o surgimento de um grande número de novas web celebridades ou micro celebridades $\mathrm{e}$ recentemente dos digital influencers, termo que designa-se a usuários que utilizam de sua popularidade em determinada rede social para divulgar um estilo de vida e até mesmo produtos de uma determinada marca patrocinadora. Viu-se a necessidade em pesquisar sobre o termo e suas vertentes, pois é uma profissão que tem gerado lucros e resultados para o mercado atualmente. (SANTOS et al, 2016, p. 1)
\end{abstract}

Parte-se da hipótese que esta nova profissão, o influenciador digital, nasce para alimentar o capitalismo contemporâneo, que tem como premissa a manutenção do consumo

\footnotetext{
${ }^{1}$ Doutora em Comunicação e Cultura pela UFRJ/ISCTE. Professora do departamento de Comunicação Social da PUCRio, Coordenadora-geral do Comunicar, Assessora de Comunicação da Reitoria e vice-líder do Grupo de Pesquisa Economia Política da Comunicação EPC PUC-Rio. É, ainda, pesquisadora do Laboratório de Estudos em Comunicação Comunitária (LECC/UFRJ) e do Grupo de Pesquisa Mídia e Memória - Construção de Identidades da Pós-Graduação em Comunicação Social da PUC Minas. A professora é integrante do Conselho Consultivo do Núcleo Interdisciplinar de Meio Ambiente (Nima) e consultora em comunicação do Centro Internacional de Estudos e Pesquisas sobre a Infância (Ciespi), ambos da PUC-Rio.

2 Disponível em: https://datareportal.com/reports/digital-2021-brazil. Acessado em 05 de julho de 2021.

3 Disponível em: https://www.comscore.com/por/lnsights/Apresentacoes-e-documentos/2021/O-estado-das-redessociais-no-Brasil. Acessado em 8 de julho de 2021.
} 
desenfreado de bens e transforma as pessoas em mercadoria. Para o sociólogo Zygmunt Bauman, esta sociedade de consumidores "representa o tipo de sociedade que promove, encoraja ou reforça a escolha de um estilo de vida e uma estratégia existencial consumistas, e rejeita todas as opções culturais alternativas" (2008, p. 71).

Para esta autora, a questão surge a partir dos debates nas aulas de Mídias Locais, disciplina ministrada no $7^{\circ}$ período do curso de Comunicação da PUC-Rio. A produção de conteúdo digital por moradores de favelas no cenário de novos ecossistemas midiáticos (CANAVILHAS, 2010) administrados pelo duopólio da internet (Google e Facebook) está no cerne das discussões. Existe uma necessidade de tentar entender de que forma os usuários de redes sociais como o Facebook e/ou Instagram podem escapar das armadilhas do capitalismo neoliberal, que se aproveita do posicionamento crítico das classes subalternas para se reinventar e absorver seus críticos, tornando-os parte do negócio (BOLTANSKY e CHIAPIELLO, 2009).

A pesquisa realizada pela Comscore, citada no início deste artigo, levantou que no Brasil, em 2020, as marcas fizeram 24,4 bilhões de publicações nas redes sociais, por meio de publishers e influenciadores. Quando comparado com o ano anterior, esse número é $25 \%$ maior. A Comscore analisou as interações feitas no Facebook, Twitter e Instagram

A pesquisa da consultoria apontou, também, que o Instagram foi a plataforma campeã em termos de share de ações no ano passado: de todas as publicações realizadas por marcas, publishers e influenciadores, $72 \%$ se concentraram no Instagram. Já em relação à audiência, o Facebook segue na liderança como a rede social de maior alcance, concentrando $65 \%$ da atenção dos usuários. Em termos gerais, o volume de comentários nas redes sociais cresceu $5 \%$ no ano passado na comparação com 2019. (SACCHITIELLO, 2021)

Dito isto, o presente trabalho articula pesquisas em Comunicação Comunitária e na Economia Política da Comunicação a partir de um estudo de caso do perfil no Instagram de Nathaly Dias, @blogueiradebaixarenda. Para Robert Yin, "estudo de caso é uma inquirição empírica que investiga um fenômeno contemporâneo dentro de um contexto da vida real, quando a fronteira entre o fenômeno e o contexto não é claramente evidente e onde múltiplas fontes de evidência são utilizadas" (2001, p.32).

Nathaly Dias tem 28 anos, é formada em Administração de Empresas e mora no Morro do Banco, uma favela na Zona Oeste do Rio de Janeiro. Seu perfil no Instagram, criado no dia 3 de outubro de 2017, nasceu com o slogan "Lifestyle do BAIXA RENDA e blogueira da vida real", e afirmava que a intenção era "(re)significar a noção de 'influência"4 atribuída aos produtores de conteúdo que comercializam, além de produtos, informação por meio de vídeos e fotos nesta rede social do Facebook.

Dias decidiu ser uma voz da parcela dos brasileiros que não usufrui do que as blogueiras de alta renda costumam ostentar nas redes sociais: apartamentos luxuosos, closets abarrotados e almoços em restaurantes chiques. O governo

\footnotetext{
${ }^{4}$ https://www.instagram.com/blogueiradebaixarenda/?hl=pt-br. Acessado em 05 novembro de 2019.
} 
federal (decreto $n^{\circ} 6135$, de 26 de junho de 2007) define como "de baixa renda" a família cujos ganhos mensais são de até três salários mínimos. (COELHO, 2019)

Nathaly, assim como muitos jovens de sua geração, tem o empreendedorismo como um dom necessário para o seu sucesso profissional e vê a internet como o espaço ideal para dar visibilidade às injustiças sociais enfrentadas por quem vive na favela. Em 2018, a jovem deixou o estágio na área financeira em uma empresa para se dedicar à produção de conteúdo para as redes sociais. O marido, Guilherme Brainer, também estudante de administração de empresas, seguiu o exemplo e abandou o estágio. Os dois renunciaram a uma remuneração mensal de $\mathrm{R} \$$ 2,1 mil para ingressar no mercado de youtubers e ganhar em média US $\$ 770$ por mês, na época cerca de $R \$ 3$ mil, com a monetização dos vídeos publicados em seu canal. Todos os dias, ela postava pela manhã um vídeo dizendo "Bom dia! Acordou para quê? Acordou para vencer! Vamos lutaaaaar!"

O acompanhamento do perfil da jovem no Instagram de 2019 a 2021 permitiu obter dados que endossam a reflexão proposta neste trabalho. No início, o bordão de Nathaly, destacado acima, era acompanhado, prioritariamente, por vídeos que a mostravam arrumando a casa, passeando pela favela, fazendo compras, procurando produtos mais baratos, como ela mesma diz: de baixa renda. Com o tempo, a esses stories foram acrescentados os que mostravam os mimos, os chamados "recebidos" 5 , que ela ganhava e, depois, postagens de entrevistas, viagens e participação em congressos. As produções ganharam patrocinadores como a empresa aérea Gol e a rede de hotéis Ibis que financiam a série de vídeos como a "Baixa renda pelo mundo" exibida no canal da blogueira no YouTube e divulgada em seu Instagram, por exemplo. Os chamados publi posts ${ }^{6}$ já a levaram ao Uruguai e à Argentina.

Nosso primeiro publi nesse site está no ARRRRRRRRRRRR! Espero que vocês gostem muito do conteúdo que fiz pensando em vocês e pra saber tudo sobre como foi nossa viagem é só clicar nesse link https://sundaycooks.com/buenosaires-... que lá ta todos os endereços de onde comemos e os lugares todos que fomos! Vai ter BAIXA RENDA EM BUENOS AIRES SIM!!!!"7

$\mathrm{Na}$ época dos primeiros publi posts Nathaly entendia que era uma voz da população de baixa renda no exterior e, consequentemente, contribuía para a ressignificação de influência digital. Mas, se pensarmos essa ressignificação de influência digital como cidadania, o caminho a ser feito ainda é longo. Como nos ensina o sociólogo Zygmunt Bauman, "a vida de consumo não pode ser outra coisa senão uma vida de aprendizado rápido, mas também precisa ser uma vida de esquecimento veloz" (2008, p.124). Questionamos se a conquista de Nathaly é apenas a conquista de Nathaly, porque favorece pouco a sua comunidade, e mais a seus patrocinadores.

\footnotetext{
5 Jargão no marketing digital para fazer referência à produtos presenteados a usuários do Instagram, que possuem um grande número de seguidores e são potenciais influenciadores para as marcas.

6 Jargão do marketing digital para fazer referência a postagens patrocinadas por empresas.

7 https://www.youtube.com/watch?v=bp86ipU8XRA\&list=PLIU63JFphs9hMHnwLcfbZmmcl9-1HhQ9i\&index=5. Acessado em 08 de julho de 2021.
} 
$E$, ainda, se essa conquista é duradoura. A resposta é mais complexa do que um mero sim ou não.

\section{A ascensão da influenciadora Nathaly Dias}

Até o fechamento deste artigo, o perfil @blogueiradebaixarenda no Instagram já tinha 213 mil seguidores e apresentava Nathaly como Mulher | Empresária | Favelada \& Criadora de Conteúdo". Sua missão de "(re)significar a noção de influência" já não existia mais como destaque, mas ao analisar 330 das suas 460 publicações é possível perceber que os publi posts passaram a ocupar um espaço importante em seu feed. A blogueira alterna publicações patrocinadas com relatos pessoais, aqueles que a fizeram ganhar fama e destaque nas redes sociais e a transformaram em assunto permanente na grande mídia. Nathaly Dias foi tema até um programa Globo Repórter da Rede Globo, no dia 27 de junho de $2021^{9}$.

Em 2019 Nathaly fez 127 postagens em seu feed, mas apenas sete eram promovendo alguma marca. A maioria apresentava suas conquistas materiais e profissionais como montar 0 primeiro home-office com seu salário de blogueira no dia 27 de março e o lançamento do canal no YouTube no dia 28 de janeiro. "A meta e termos pelo menos 1000 inscritos daqui indo para lá", pedia a blogueira no post. Apesar de poucos publi posts, Nathaly construía neste momento em seu Canal no YouTube a base para o seu futuro como influenciadora digital no Instagram. Neste ano ela firmou a parceria já citada com empresa aérea Gol e a rede de hotéis lbis para a realização da série "Baixa renda pelo mundo".

Em 2020, apesar da pandemia do COVID-19 impedir as viagens, a blogueira ampliou o número de patrocinadores de sua rede social: das 115 publicações feitas, 23 receberam a hastag \#publi. Empresas como a Continental Brasil, Serasa, Leroy Merlin, Veja Limpeza, OLX, Telecine, UBER e a instituição de ensino a distância paranaense UniCesumar passaram a fazer parte do cardápio de posts da blogueira. As marcas são sempre inseridas a um roteiro que transita sempre nas suas histórias pessoais e/ou no universo da população de baixa renda. A Heinz do Brasil, por exemplo, teve a sua iniciativa de doação de cestas básicas.

Eu amo quando marcas legais me procuram pra eu transmitir a vocês iniciativas incríveis que podem ajudar a vida de milhares de pessoas $\varnothing$

@heinz_br está doando cestas com os 6 ingredientes do MELHOR KETCHUP DO MUNDO para a @gastromotiva, que é uma ONG que além de oferecer alimentação pra galera em situação de vulnerabilidade também oferece profissionalização para que a comida seja um agente transformador da realidade.

Com essa doação a ONG vai conseguir estender seu trabalho pra além do Rio, vamos conseguir levar comida pra galera de São Paulo também!

Conheça mais sobre o projeto nos perfis @heinz_br e @gastromotiva \#cestaheinz $^{10}$

\footnotetext{
${ }^{8}$ https://www.instagram.com/blogueiradebaixarenda/?hl=pt-br. Acessado em 09 de julho de 2021.

9 https://globoplay.globo.com/v/9636450/programa/. Acessado em 09 de julho de 2021.

10 Post do dia 13 de maio de 2020; Disponível em https://www.instagram.com/p/CAlj2ecglld/. Acessado em 06 de julho de 2021.
} 
Já para o lançamento da nova fase digital da Continental Brasil, a blogueira recorreu à sua própria história para valorizar os eletrodomésticos da marca.

Se tem uma expressão que eu posso usar com a @continentalbrasil é "EU FUI, EU TAVA"

Hoje venho contar a vocês meus Baixa Rendinhas que a Continental voltou e chegou com tudo trazendo um novo conceito: O ATUALIZA! Totalmente repaginada e com o objetivo de mostrar que lugar de MULHER É ONDE ELA QUISER!

Porém minha história com a Continental não começou agora...

Lembram da história que eu sempre conto por aqui da época que minha mãe se separou do meu pai com a mão na frente e outra atrás?

Nessa época ganhamos um colchão de casal, uma geladeira velha dos meus avós, um ventilador usado de uma tia, o primeiro salário da minha mãe foi pra comprar um fogão e o nosso guarda-roupa era a caixa de papelão que o fogão veio dentro.

Então... Esse fogão era um da Continental e na moral, que coisa linda poder olhar pra trás e ver essa trajetória. É sobre isso $<3$

Tem muita coisa boa vindo por aí, acompanhe eu a Conti pelo @continentalbrasil Será que a geladeira vem, BRASIL??? 00

\#ChegouANovaGeração \#AtualizaContinental \#publi1

A estratégia deu tão certo que de acordo com a reportagem da Revista Veja Rio, Nathaly fechou 2020 com um faturamento de meio milhão de reais. Além disso, ela se orgulha de ter realizado o sonho de tornar a mãe, que trabalhava como empregada doméstica, em sócia da empresa que administra a carreira dela. "A favela tem médico, advogado, engenheiro. E agora tem blogueira também. A pobreza não pode mais ser representada daquele jeito estereotipado que estamos acostumados a ver na televisão" (DIAS, apud CAPOBIANCO, 2021).

Em 2021 os trabalhos continuaram em alta, de janeiro a 10 de julho Nathaly fez 88 publicações no Instagram, sendo 24 publi posts. Um número superior a todo ano anterior. Empresas como a Microsoft passaram a integrar a lista de clientes da blogueira de baixa renda, que no dia 4 de julho foi nomeada embaixadora da Google. Outras empresas, como a UBER e a UniCesumar, reforçaram a parceria iniciada em 2020. As postagens passaram a receber a hastag \#publidablo, uma referência à publicidade da blogueira. Nathaly mescla as postagens feitas para seus patrocinadores com as que falam da sua vida pessoal: desde sua separação do marido até a divulgação de todas as suas conquistas materiais.

\section{Considerações finais}

Nathaly Dias ingressou no mercado de trabalho dos influenciadores digitais sem a pretensão de estimular o consumo e sim para apresentar nas redes sociais a vida real de uma jovem que vive em uma favela do Rio de Janeiro. Mas, o fato é que as marcas investem cada vez mais em pequenos influenciadores para divulgar seus produtos. Vale mais uma vez lembrar dos dados obtidos pela pesquisa da consultoria Comscore, que chama a atenção para o fato de

${ }_{11}$ Post do dia 15 de agosto e 2020. Disponível em https://www.instagram.com/p/CD6p0TkAeVi/. Acessado em 06 de julho de 2021. 
que o Instagram concentrou $72 \%$ das ações das marcas por meio de influenciadores, sendo a maioria desses produtores de conteúdo com o perfil da Nathaly. "Entre os assuntos e conteúdos produzidos por influenciadores, os temas que mais ampliaram o engajamento foram lifestyle e assuntos gerais (141\% mais), perfis de comédia (aumento de 93\%) e empreendedorismo (78\%)." (SACCHITIELLO, 2021).

Ao criar conteúdos que promovem um mix entre a sua vida pessoal e os produtos de seus clientes, Nathaly faz exatamente o que está dando certo, no que diz respeito a promover engajamento entre as marcas e seus potenciais consumidores. Ela que fez seu primeiro vídeo porque viu em um shopping do Rio de Janeiro um pano de prato que custava $R \$ 30$ e resolveu mostrar outros mais bonitos que tinha comprado a $R \$ 10$, se transformou em uma agente da manutenção da essência do capitalismo contemporâneo, o consumismo. Ela não mostra apenas os produtos mais baratos, mas sim divulga, por exemplo, a marca UBER, que para muitos pesquisadores é uma das empresas que melhor representam a precarização do trabalho na contemporaneidade. Por outro lado, é preciso ressaltar que ao se tornar influenciadora digital Nathaly colocou a favela e sua população no cenário da publicidade e, principalmente, transformou a blogueira em uma consumidora em potencial.

\section{Referências Bibliográficas}

BAUMAN, Zygmunt. Vida para consumo: A transformação das pessoas em mercadoria. Rio de Janeiro: Jorge Zahar Ed., 2008.

BOLAÑO, César. Economia Política da Internet vol. 2: jornalismo online. São Cristóvão-SE: Editora, 2017. BOLTANSKY, Luc e CHIAPIELLO, Ève. (2009). O novo espírito do capitalismo. São Paulo: Editora WMF Martins Fontes.

CANAVILHAS, João. (2010) O novo ecossistema mediático. Disponível em: http://www.bocc.ubi.pt/pag/canavilhas-joao-o-novo-ecossistema-mediatico.pdf. Acessado em 16 de junho de 2019.

CASTELLS, Manuel. (2015). O poder da Comunicação. São Paulo/Rio de Janeiro: Paz e Terra.

CAPOBIANCO, Marcela. "Irreverentes, influenciadores de favelas entram na mira das marcas - Uma turma de jovens criativos egressos das comunidades explora sem vergonha sua origem humilde nas redes e faz (muito) sucesso", Revista Veja Rio, 18 de junho de 2021. Disponível em https://vejario.abril.com.br/cidade/influenciadores-favelas/. Acessado em 10 de julho de 2021.

COELHO, TIAGO. "Um teto todo seu - conquistas de uma blogueira", Revista Piauí, edição 155, de agosto de 2019. Disponível em https://piaui.folha.uol.com.br/materia/um-teto-todo-seu/. Acessado em 09 de julho de 2021.

PERUZZO, Cicilia. (2006) Revisitando os Conceitos de Comunicação Popular, Alternativa e Comunitária. Trabalho apresentado ao Núcleo de Pesquisa "Comunicação para Cidadania", do XXIX Congresso Brasileiro de Ciências da Comunicação, Brasília-DF, INTERCOM

SACCHITIELLO, Bárbara. "Como e com quais assuntos os brasileiros engajam nas redes? Estudo da Comscore apontou um aumento do tempo passado nas plataformas e da interação das pessoas com marcas, publishers e influenciadores. Meio\&Mensagm, 26 de maio de 2021. Disponível em 
https://www.meioemensagem.com.br/home/midia/2021/05/26/como-e-com-quais-assuntos-os-brasileirosengajam-nas-redes-sociais.html. Acessado em 09 de julho de 2021.

SANTOS, Samir et al. "Gabriela Pugliesi: uma análise sobre o marketing de influência na rede social Instagram". Artigo apresentado no XVIII Congresso de Ciências da Comunicação na Região Nordeste Caruaru - PE - 07 a 09/07/2016 e publicado nos Anais do evento.

Disponível em https://www.portalintercom.org.br/anais/nordeste2016/resumos/R52-0157-1.pdf. Acessado em 04/07/2021.

YIN, Robert K. Estudo de caso: planejamento e métodos. 2ª ed. Porto Alegre: Bookman, 2001 